\title{
Serum level of IL-10 and IL-10-1082G/A polymorphism are associated with the risk of ischemic stroke: A meta-analysis
}

\section{Xiaodong Rui}

Liyang

\section{Yeqin Sha}

nanjing medical university

\section{Shuang Wen}

Nanjing Medical University

\section{Qingyang Sun}

Nanjing medical university

Jingming $\mathrm{Hu}$

Nanjing medical university

\section{Fengfeng Yan}

Nanjing medical university

lianping he ( $\nabla$ lianpinghe@126.com )

Anhui Polytechnic University https://orcid.org/0000-0002-9627-5599

Guanghui Xie

Nanjing medical university

\section{Research}

Keywords: Interleukin-10, Single Nucleotide Polymorphism, Stroke, Meta-Analysis

Posted Date: January 27th, 2020

DOI: https://doi.org/10.21203/rs.2.21934/v1

License: (1) (1) This work is licensed under a Creative Commons Attribution 4.0 International License. Read Full License 


\section{Abstract}

\section{BACKGROUND}

Stroke is one of the leading causes of disability and mortality among adults worldwide. The aim of the study was to confirm the relationship of serum interleukin-10 (IL-10) and its gene polymorphism with the risk of ischemic stroke (IS).

\section{METHODS}

PubMed and China Wanfang database were systematically searched up to September 2, 2019. Studies illustrating on the association between serum IL-10 or IL-10-1082G/A, IL-10-819C/T, IL-10-592C/A polymorphisms and IS susceptibility were included in this study. Newcastle-Ottawa scale was used to assess the study quality. RevMan 5.3 was used for statistical analysis.

\section{RESULTS:}

Seventeen case-control studies were included in this meta-analysis which provides 3754 patients with IS and 5064 controls. Combined analysis indicated that patients with IS had lower serum level of IL-10 (Mean difference [MD]: $-4.25 ; 95 \%$ confidence interval [CI]: -6.14 to $-2.36, p<0.0001$ ). An association was identified between IL-10-1082G/A polymorphism and the risk of IS, but no association was found between polymorphism of IL-10-819C/T or IL-10-592C/A and the risk of IS when all ethnic groups were considered together. For IL-10-1082G/A polymorphism, individuals with AA-genotype might have an increased risk of IS among Chinese Han population while no such correlation was observed in other ethnic group.

CONCLUSION

This meta-analysis suggested that low serum level of IL-10 and IL-10-1082G/A polymorphism may be associated with the risk of IS. More clinical studies should be conducted to confirm the relationship between serum IL-10 level and the risk of IS in all ethnic groups.

\section{Background}

Stroke is one of the leading causes of disability and mortality among adults worldwide, about $85 \%$ of stroke cases are ischemic, whereas $15 \%$ are hemorrhagic. Ischemic stroke (IS) is a focal neurologic deficit syndrome because of sudden occlusion of a cerebral artery by thrombus, causing ischemia cerebral hypoxia. Stroke mortality rate is high in developing countries, which accounts for two-thirds of stroke mortality worldwide[1]. It is estimated that the burden of IS will increase in the next 20 years with increasing number of older adults in developing countries.

IS can be attributed to both genetic and environmental factors, genetic susceptibility may be closely related to the development of IS. Interleukins $10(\mathrm{IL}-10)$ as a key inflammatory cytokine plays a vital role in 
various pathophysiological process[2]. There are lots of studies on the relationship between serum level of IL-10 or IL-10 gene polymorphism and the risk of ischemic stroke. Due to difference of sample size and region, the conclusion of research is controversial.

The objective of this meta-analysis was to investigate the association of serum level of IL-10 and several IL-10 gene polymorphism with the risk of IS.

\section{Methods}

This meta-analysis was executed according to the 2016 Preferred Reporting Items for Systematic Review and Meta-analysis (PRISMA) statement[3].

\section{Search Strategy}

Eligible articles were searched by electronic database of PubMed and China Wanfang to up to September 2 2019. The terms consist of Interleukin-10 and ischemic stroke.

\section{Eligibility Criteria}

Eligible studies must meet the following four criteria: 1) all studies should evaluate the relationship between serum level of IL-10, IL-10-1082A/G, IL-10-819C/T or IL-10-592C/A gene polymorphism and IS risk; 2) all studies had to be a case-control design; 3 ) all study cases should be diagnosed as ischemic stroke; 4$)$ genotype distributions in both cases and controls were available to calculate an odds ratio (OR) with $95 \%$ confidence interval $(\mathrm{Cl}) ; 5)$ Blood samples of ischemic stroke patients were collected at admission. Exclusion criteria: 1) Reviews, abstracts or animal studies. 2) study was not relevant to IL-10 serum level, gene polymorphism or IS; 3 ) study has no target outcomes.

Two investigators (Yeqin Sha and Xiaodong Rui) independently screened the articles. Eligible articles were included through reading the full text in detail.

\section{Quality Assessment}

Newcastle-Ottawa Scale[4] (NOS) was used to evaluate the quality of articles included. All seventeen studies were evaluated strictly and scored at least 6 points (Table 1). 
Table 1

Quality Assessment of Included Studies According to the Newcastle-Ottawa Scale

\begin{tabular}{|c|c|c|c|c|c|c|c|c|c|}
\hline Item/study & $A D$ & $\mathrm{RA}$ & scs & DCS & CIF & EA & SMA & NR & Total score \\
\hline Xie[7] & 1 & 0 & 1 & 1 & 2 & 1 & 1 & 1 & 8 \\
\hline Kes[8] & 1 & 0 & 0 & 1 & 1 & 1 & 1 & 1 & 6 \\
\hline Singh[9] & 1 & 0 & 0 & 1 & 1 & 1 & 1 & 1 & 6 \\
\hline Zhang[10] & 1 & 0 & 1 & 1 & 0 & 1 & 1 & 1 & 6 \\
\hline $\operatorname{Jin}[11]$ & 1 & 0 & 1 & 1 & 0 & 1 & 1 & 1 & 6 \\
\hline Li[12] & 1 & 0 & 1 & 1 & 1 & 1 & 1 & 1 & 7 \\
\hline $\mathrm{He}[13]$ & 1 & 0 & 1 & 1 & 1 & 1 & 1 & 1 & 7 \\
\hline Jiang[14] & 1 & 0 & 0 & 1 & 1 & 1 & 1 & 1 & 6 \\
\hline Liu[15] & 1 & 0 & 1 & 1 & 1 & 1 & 1 & 1 & 7 \\
\hline Tong[16] & 1 & 0 & 1 & 1 & 1 & 1 & 1 & 1 & 7 \\
\hline Ozkan[17] & 1 & 0 & 1 & 1 & 1 & 1 & 1 & 1 & 7 \\
\hline Munshi[18] & 1 & 0 & 0 & 1 & 1 & 1 & 1 & 1 & 6 \\
\hline Kumar[19] & 1 & 0 & 1 & 1 & 2 & 1 & 1 & 1 & 8 \\
\hline Sultana[20] & 1 & 0 & 0 & 1 & 1 & 1 & 1 & 1 & 6 \\
\hline Belisário[21] & 1 & 0 & 1 & 1 & 1 & 1 & 1 & 1 & 7 \\
\hline Marousi[22] & 1 & 0 & 1 & 1 & 1 & 1 & 1 & 1 & 7 \\
\hline Tuttolomondo[23] & 1 & 0 & 1 & 1 & 1 & 1 & 1 & 1 & 7 \\
\hline \multicolumn{10}{|c|}{$\begin{array}{l}\text { Note: Adequate definition of cases(AD); Representitiveness of cases(RA); Selection of control } \\
\text { subjects(SCS); Definition of control subjects(DCS); Control for important factor or additional } \\
\text { factor(CIF); Exposure assessment(EA); Same method of ascertainment for all subjects(SMA); } \\
\text { Nonresponse rate(NR). }\end{array}$} \\
\hline
\end{tabular}

\section{Statistical analysis}

Review Manager 5.3 (Cochrane IMS) was used for this meta-analysis. Random-effects model was conducted when heterogeneity is existing. Q-square test and the $\mathrm{I}^{2}$ index was calculated to assess the heterogeneity, $I^{2} \varangle 50 \%$ defined as significant heterogeneity. Hardy-Weinberg equilibrium (HWE) in the control group of articles included was examined by using Chi-square test. The dichotomous data of metaanalysis were reported as odds ratio (OR) and corresponding $95 \%$ confidence intervals (Cls). The mean difference (MD) and the associated $95 \% \mathrm{Cl}$ were calculated for continuous variables. In order to combine 
results, the sample mean and standard deviation were estimated if the study reported median and interquartile range using the methods reported by Wan[5] and Luo[6].

\section{Results}

\section{Retrieved studies}

Based on our search strategy, 387 eligible studies were screened. The titles and abstracts of these studies were filtrated according to inclusion criteria. Finally, seventeen full text articles were eligible for this metaanalysis[7-23] (Fig. 1).

\section{Study Characteristics}

Three studies were included on the relationship between serum IL-10 level and ischemic stroke, including 274 patients. A total of fourteen studies which involved 3480 patients with IS were included to explore the relationship between IL-10-1082G/A polymorphism and the risk of IS. There are seven studies involving 1604 patients on the relationship between IL-10-819C/T polymorphism and the risk of IS. In addition, four studies were included to explore the association of IL-10-592C/A polymorphism with the risk of IS, involving 1040 patients.

\section{Publication Bias}

A comprehensive design was used in our study to minimize the publication bias. We have two researchers (Yeqin Sha and Xiaodong Rui) performed an intact search strategy and selected studies strictly according to the eligibility criteria and exclusion criteria. Finally, we used heterogeneity test to assess possible publication bias. In this system evaluation no evidence of publication bias was found.

\section{Quantitative Synthesis}

The results of this meta-analysis and heterogeneity test were shown in Table 2. We estimated the relationship between serum level of IL-10 or gene polymorphism and the risk of ischemic stroke with the dominant model and the recessive model. 
Table 2

ssociation Between IL-10 Gene Polymorphisms and Ischemic Stroke

\begin{tabular}{|c|c|c|c|c|c|c|}
\hline \multicolumn{5}{|c|}{ Association } & \multicolumn{2}{|c|}{ Heterogeneity } \\
\hline Genetic model & Subgroup & OR $(95 \% \mathrm{Cl})$ & $\mathrm{P}$ & Effect model & $\mathrm{I}^{2}(\%)$ & $P_{\text {het }}$ \\
\hline \multicolumn{7}{|l|}{ IL-10-1082G/A } \\
\hline \multirow[t]{3}{*}{ A vs. $G$} & Overall & $1.20(0.96-1.49)$ & 0.11 & $\mathrm{R}$ & 78 & 0.000 \\
\hline & Chinese & $1.30(0.99-1.71)$ & 0.06 & $\mathrm{R}$ & 63 & 0.01 \\
\hline & Other & $1.11(0.77-1.59)$ & 0.58 & $\mathrm{R}$ & 86 & 0.000 \\
\hline \multirow[t]{3}{*}{$A A$ vs. $A G+G G$} & Overall & $1.32(1.02-1.70)$ & 0.04 & $\mathrm{R}$ & 63 & 0.001 \\
\hline & Chinese & $1.58(1.15-2.17)$ & 0.005 & $\mathrm{R}$ & 49 & 0.07 \\
\hline & Other & $1.08(0.72-1.60)$ & 0.72 & $\mathrm{R}$ & 68 & 0.005 \\
\hline \multirow[t]{3}{*}{$A A+A G$ vs. $G G$} & Overall & $1.23(0.89-1.70)$ & 0.34 & $\mathrm{R}$ & 71 & 0.000 \\
\hline & Chinese & $1.46(1.17-1.83)$ & 0.001 & $\mathrm{R}$ & 0 & 0.64 \\
\hline & Other & $1.10(0.65-1.89)$ & 0.72 & $\mathrm{R}$ & 83 & 0.000 \\
\hline \multicolumn{7}{|l|}{ IL-10-819C/T } \\
\hline T vs. C & Overall & $0.99(0.89-1.11)$ & 0.92 & $\mathrm{~F}$ & 0 & 0.47 \\
\hline TT vs. $T C+C C$ & Overall & $0.95(0.82-1.10)$ & 0.51 & $\mathrm{~F}$ & 0 & 0.57 \\
\hline TT + TC vs. CC & Overall & $1.09(0.88-1.35)$ & 0.45 & $\mathrm{~F}$ & 47 & 0.08 \\
\hline \multicolumn{7}{|l|}{ IL-10- 592C/A } \\
\hline A vs. C & Overall & $1.06(0.93-1.21)$ & 0.37 & $\mathrm{~F}$ & 39 & 0.18 \\
\hline$A A$ vs. $A C+C C$ & Overall & $1.15(0.83-1.61)$ & 0.40 & $\mathrm{R}$ & 54 & 0.09 \\
\hline$A A+A C$ vs. $C C$ & Overall & $1.10(0.84-1.44)$ & 0.50 & $\mathrm{~F}$ & 0 & 0.78 \\
\hline
\end{tabular}

Combined analysis indicated that patients with ischemic stroke had significantly lower serum level of IL10 (Mean difference [MD]: -4.00; 95\% confidence interval [Cl]: -4.73 to -3.27, Fig. 2.). Funnel plot was implemented in this study and no substantial asymmetry was identified (Fig. 3).

The association between IL-10-1082G/A gene polymorphism and the risk of IS was then explored and significant heterogeneity was found among different ethnicities, therefore sub-group analysis was used. We conducted two subgroups, namely Chinese population and other ethnic groups. It demonstrated that significant association was observed between IL-10-1082G/A polymorphism and the risk of IS among 
Chinese population (for $A A$ vs. $A G+G G: O R=1.58,95 \% \mathrm{Cl}: 1.15-2.17, P=0.005$, Fig. 4) but for other ethnic groups (for AA vs. $G A+G G$ : $O R=1.08,95 \% \mathrm{Cl}: 0.72-1.60, P=0.72$, Fig. 4). Therefore, individuals with AAgenotype might have an increased risk of IS among Chinese Han population.

However, no association was found between polymorphism of IL-10-819C/T and IL-10- 592C/A (TT vs. TC + CC for IL-10-819C/T: OR = 0.95, 95\% Cl: 0.82-1.10, P = 0.51, Fig. 5; AA vs. AC + CC for IL-10-592C/A: $\mathrm{OR}=1.15,95 \% \mathrm{Cl}: 0.83-1.61, \mathrm{P}=0.40$, Fig. 6 ) and the risk of IS among population.

\section{Discussion}

Our meta-analysis was the first study to show that lower serum level of IL-10 was closely associated with the risk of IS although the association of IL-10 gene polymorphism and the risk of IS had been explored before. We also confirmed that IL-10-1082G/A polymorphism had significant correlation with the risk of IS in Chinese Han population. Other ethnicities didn't show such association. In previous study, it is indicated that IL-10-1082G/A is associated with the risk of IS in Asian population, however, between-study heterogeneity is remarkable in their study[24]. Our study successfully solved the high heterogeneity by subgroup analysis, finding significant correlation between IL-10-1082G/A polymorphism and the risk of IS among Chinese population. However, the heterogeneity in subgroup of other ethnic groups was still high, due to small sample size, different regions and limited number of case-control studies.

Furthermore, our meta-analysis examined other common gene polymorphisms of IL-10 promoter region such as IL-10-819C/T and IL-10-592C/A and showed no correlation with the risk of IS. Considering the limited number of case-control studies exploring the correlation between IL-10-819C/T and IL-10-592C/A polymorphism and the risk of IS, more studies is needed to clarify its association. Therefore, our result suggested that IL-10-1082G/A may be the only one which is associated with IS susceptibility.

Despite of the strict retrieval, statistical quality control, publication bias test mentioned above, the current study still has some limitations that should be addressed. In the future, we need more high-quality study which involves more ethnic and regional population, makes a comprehensive evaluation of relationship between serum level of IL-10 or IL-10 gene polymorphism and the risk of IS.

\section{Conclusion}

This meta-analysis suggested that the lower serum level of IL-10 was closely related to high risk of IS. IL10-1082G/A polymorphism may be associated with the risk of IS in Chinese population. More clinical studies should be conducted to confirm the relationship between the serum level of IL-10 and the risk of IS and the relationship between lower serum level of IL-10 and IL-10 promotor gene polymorphism can be explored further.

\section{Declarations}

\section{Ethical Approval and Consent to participate}


Not applicable.

Consent for publication

Not applicable.

Availability of supporting data

Competing interests

The authors declare that they have no competing interests.

Funding

No funding was received in this work.

Authors' contributions

All authors contributed to data analysis, drafting and revising the article, gave final approval of the version to be published, and agree to be accountable for all aspects of the work.

Acknowledgements

Not applicable.

\section{References}

1. Brainin $M$, Teuschl $Y$, Kalra L: Acute treatment and long-term management of stroke in developing countries. Lancet Neurol 2007, 6:553-561.

2. Arponen O, Muuronen A, Taina M, Sipola P, Hedman M, Jakala P, Vanninen R, Pulkki K, Mustonen P: Acute phase IL-10 plasma concentration associates with the high risk sources of cardiogenic stroke. PLoS One 2015, 10:e0120910.

3. Preferred reporting items for systematic review and meta-analysis protocols (PRISMA-P) 2015: elaboration and explanation. Bmj 2016, 354:i4086.

4. Stang A: Critical evaluation of the Newcastle-Ottawa scale for the assessment of the quality of nonrandomized studies in meta-analyses. Eur J Epidemiol 2010, 25:603-605.

5. Wan X, Wang W, Liu J, Tong T: Estimating the sample mean and standard deviation from the sample size, median, range and/or interquartile range. BMC Med Res Methodo/ 2014, 14:135.

6. Luo D, Wan X, Liu J, Tong T: Optimally estimating the sample mean from the sample size, median, mid-range, and/or mid-quartile range. Stat Methods Med Res 2018, 27:1785-1805.

7. Xie G, Myint PK, Zaman MJ, Li Y, Zhao L, Shi P, Ren F, Wu Y: Relationship of serum interleukin-10 and its genetic variations with ischemic stroke in a Chinese general population. PLoS One 2013, 8:e74126. 
8. Basic Kes V, Simundic AM, Nikolac N, Topic E, Demarin V: Pro-inflammatory and anti-inflammatory cytokines in acute ischemic stroke and their relation to early neurological deficit and stroke outcome. Clin Biochem 2008, 41:1330-1334.

9. Singh HV, Pandey A, Shrivastava AK, Raizada A, Singh SK, Singh N: Prognostic value of neuron specific enolase and IL-10 in ischemic stroke and its correlation with degree of neurological deficit. Clin Chim Acta 2013, 419:136-138.

10. Zhang GP, S.; Du, R.; Lu, B.; Li, W.;: The correlation between gene polymorphism of IL-10-819C/T and -1082G/A and cerebral infarction. Chinese Journal of Cerebrovascular Diseases 2007, 4:294-297.

11. Jin L, Ni P, Wu J, Fu Y, Ge H: The correlation between gene polymorphism of IL-10-819C/T and1082G/A and cerebral infarction. Lab Med 2011, 11:717-721.

12. Li WZ, Gao CY, He WL, Zhang HM: Association of the interleukin-10 gene-1082A/G genetic polymorphism with risk of ischemic stroke in a Chinese population. Genet Mol Res 2016, 15.

13. He W, Song H, Ding L, Li C, Dai L, Gao S: Association between IL-10 gene polymorphisms and the risk of ischemic stroke in a Chinese population. Int J Clin Exp Pathol 2015, 8:13489-13494.

14. Jiang $X H$, Lin KX, Zhang YX, Chen RH, Liu N: Correlating interleukin-10 promoter gene polymorphisms with human cerebral infarction onset. Neural Regen Res 2015, 10:1809-1813.

15. Liu X, Li Q, Zhu R, He Z: Association of IL-10-1082A/G Polymorphism with Ischemic Stroke: Evidence from a Case-Control Study to an Updated Meta-Analysis. Genet Test Mol Biomarkers 2017, 21:341350 .

16. Tong Y, Jiang S, Cai L, Guan X, Hou S, Wang Z, Lu Q, Liu J: Identification of Functional Genetic Polymorphisms at IL-10 Promoter Region and their Association with Risk of Ischemic Stroke in Chinese Han Population. J Nutr Health Aging 2018, 22:779-784.

17. Ozkan A, Silan F, Uludag A, Degirmenci Y, Ozisik Karaman HI: Tumour necrosis factor alpha, interleukin 10 and interleukin 6 gene polymorphisms of ischemic stroke patients in south Marmara region of Turkey. Int J Clin Exp Pathol 2015, 8:13500-13504.

18. Munshi A, Rajeshwar K, Kaul S, Al-Hazzani A, Alshatwi AA, Sai Babu M, Usha A, Jyothy A: Interleukin10-1082 promoter polymorphism and ischemic stroke risk in a South Indian population. Cytokine 2010, 52:221-224.

19. Kumar P, Kumar A, Sagar R, Misra S, Faruq M, Suroliya V, Vivekanandhan S, Srivastava AK, Prasad K: Association between Interleukin-10 -1082G/A Gene Polymorphism and Risk of Stroke in the North Indian Population: A Case-Control Study. J Stroke Cerebrovasc Dis 2016, 25:461-468.

20. Sultana S, Kolla VK, Jeedigunta Y, Penagaluru PK, Joshi S, Rani PU, Reddy PP: Tumour necrosis factor alpha and interleukin $\mathbf{1 0}$ gene polymorphisms and the risk of ischemic stroke in south Indian population. J Genet 2011, 90:361-364.

21. Belisario AR, Sales RR, Toledo NE, Velloso-Rodrigues C, Silva CM, Viana MB: Interleukin-10 haplotypes are not associated with acute cerebral ischemia or high-risk transcranial Doppler in a newborn cohort of 395 children with sickle cell anemia. Rev Bras Hematol Hemoter 2017, 39:108114. 
22. Marousi S, Ellul J, Antonacopoulou A, Gogos C, Papathanasopoulos P, Karakantza M: Functional polymorphisms of interleukin $\mathbf{4}$ and interleukin $\mathbf{1 0}$ may predict evolution and functional outcome of an ischaemic stroke. Eur J Neurol 2011, 18:637-643.

23. Tuttolomondo A, Di Raimondo D, Forte GI, Casuccio A, Vaccarino L, Scola L, Pecoraro R, Serio A, Clemente G, Arnao V, et al: Single nucleotide polymorphisms (SNPs) of pro-inflammatory/antiinflammatory and thrombotic/fibrinolytic genes in patients with acute ischemic stroke in relation to TOAST subtype. Cytokine 2012, 58:398-405.

24. Jin J, Li W, Peng L, Chen J, Li R, Wu P, Tan S: Relationship between interleukin-10 -1082A/G polymorphism and risk of ischemic stroke: a meta-analysis. PLoS One 2014, 9:e94631.

\section{Figures}

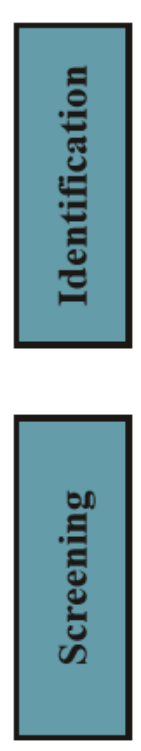

387 records identified from

pubmed and Wanfang databases
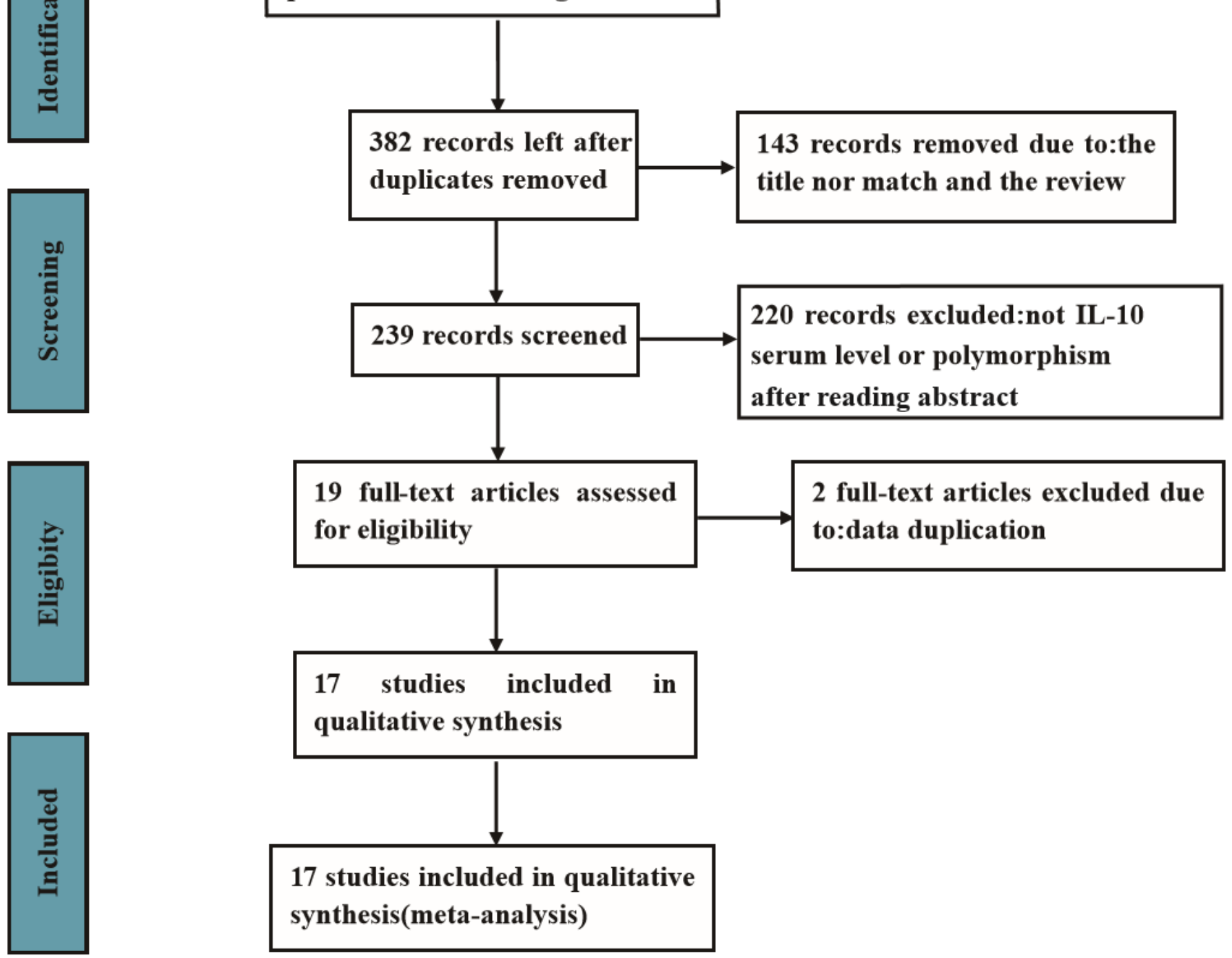
Figure 2

Flowchart for screening articles eligible

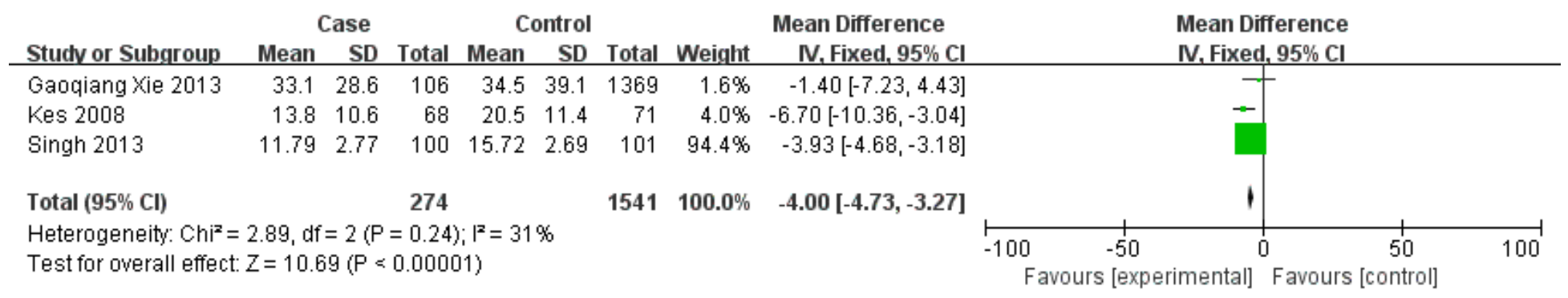

\section{Figure 4}

Forest plot for the relationship between ischemic stroke and serum IL-10 level

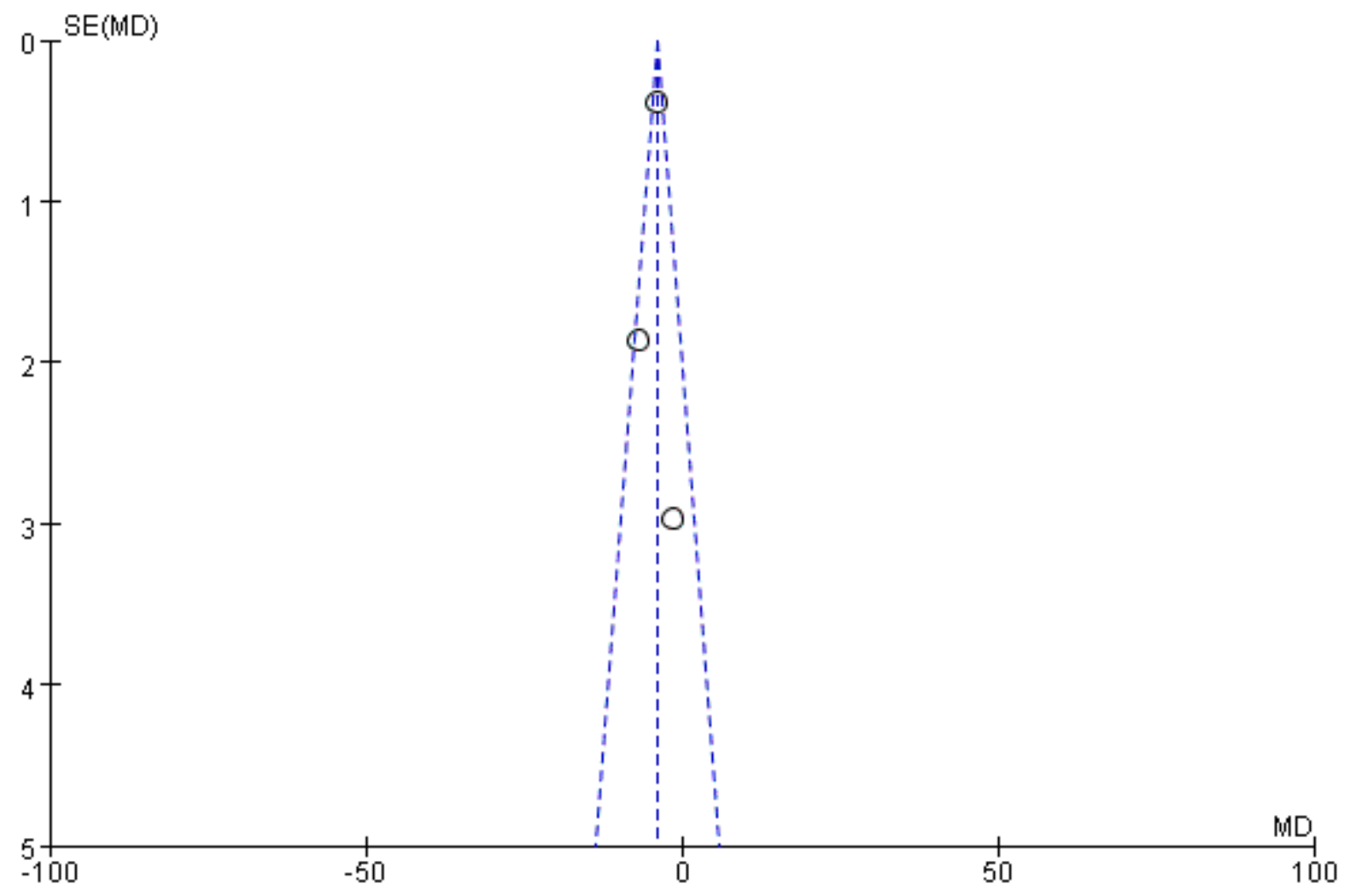

\section{Figure 6}

Funnel plot for the relationship between ischemic stroke and serum IL-10 level 
Case Control Odds Ratio

Studv or Subgroup Events Total Events Total Weight $\mathrm{M}-\mathrm{H}$, Random, 95\% Cl

1.2.1 Chinese Han population

$\begin{array}{lrrrrrr}\text { Lei Jin 2011 } & 161 & 189 & 78 & 92 & 6.7 \% & 1.03[0.51,2.07] \\ \text { Xu Liu 2017 } & 313 & 386 & 308 & 386 & 10.4 \% & 1.09[0.76,1.55] \\ \text { Wen He 2015 } & 41 & 260 & 29 & 260 & 8.6 \% & 1.49[0.90,2.48] \\ \text { W.Z. Li 2016 } & 54 & 335 & 34 & 335 & 9.2 \% & 1.70[1.08,2.69] \\ \text { Y. Tong 2018 } & 641 & 648 & 634 & 648 & 4.9 \% & 2.02[0.81,5.04] \\ \text { Xinhong Jiang 2015 } & 153 & 181 & 83 & 115 & 7.9 \% & 2.11[1.19,3.74] \\ \text { Guzhong Zhang 2007 } & 202 & 204 & 120 & 131 & 2.4 \% & 9.26[2.02,42.48] \\ \text { Subtotal (95\% Cl) } & & 2203 & & \mathbf{1 9 6 7} & \mathbf{5 0 . 0} \% & \mathbf{1 . 5 8}[1.15,2.17]\end{array}$

$\begin{array}{lcc}\text { Total events } & 1565 & 1286 \\ \text { Heterogeneity: } \text { Tau }^{2}=0.08 ; \mathrm{Ch}^{2}=11.78, \mathrm{df}=6(\mathrm{P}=0.07) ; \mathrm{I}^{2}=49 \%\end{array}$

Test for overall effect: $Z=2.82(P=0.005)$

1.2.2 Other ethnic groups

Adile Ozkan 2011

Shehnaz Sultana 2011

Belisário 2017

Marousi 2011

Anjana Munshi 2010

Tuttolomondo 2012

Pradeep Kumar 2016

Subtotal $(95 \% \mathrm{Cl})$

Total events

$\begin{array}{rr}11 & 42 \\ 154 & 238 \\ 9 & 26 \\ 47 & 145 \\ 92 & 480 \\ 58 & 96 \\ 11 & 250 \\ & 1277\end{array}$

$19 \quad 48 \quad 5.0 \%$

$0.54[0.22,1.33]$

$0.71[0.48,1.05]$

$0.76[0.33,1.74]$

$0.83[0.51,1.35]$

$1.53[1.08,2.17]$

$2.14[1.06,4.32]$

$2.83[0.89,9.01]$

1.08 [0.72, 1.60]

Heterogeneity: $\mathrm{Tau}^{2}=0.17 ; \mathrm{Chi}^{2}=18.57, \mathrm{df}=6(\mathrm{P}=0.005) ; \mathrm{I}^{2}=68 \%$

Test for overall effect: $Z=0.36(P=0.72)$

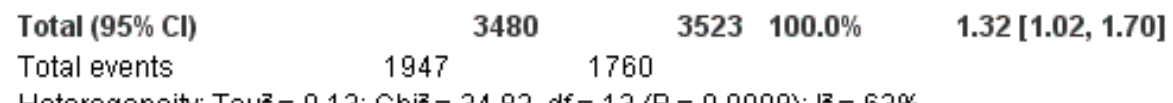

Heterogeneity: $\operatorname{Tau}^{2}=0.13 ; \mathrm{Chi}^{2}=34.82, \mathrm{df}=13(\mathrm{P}=0.0009) ; \mathrm{I}^{2}=63 \%$

Test for overall effect: $Z=2.09(P=0.04)$

Test for subaroun differences: $\mathrm{Chi}^{2}=2.18 \mathrm{df}=1(\mathrm{P}=0.14) \cdot \mathrm{I}^{2}=54.2 \%$

\section{Figure 7}

Forest plot for the relationship between IL-10-1082G/A polymorphism and the risk of IS

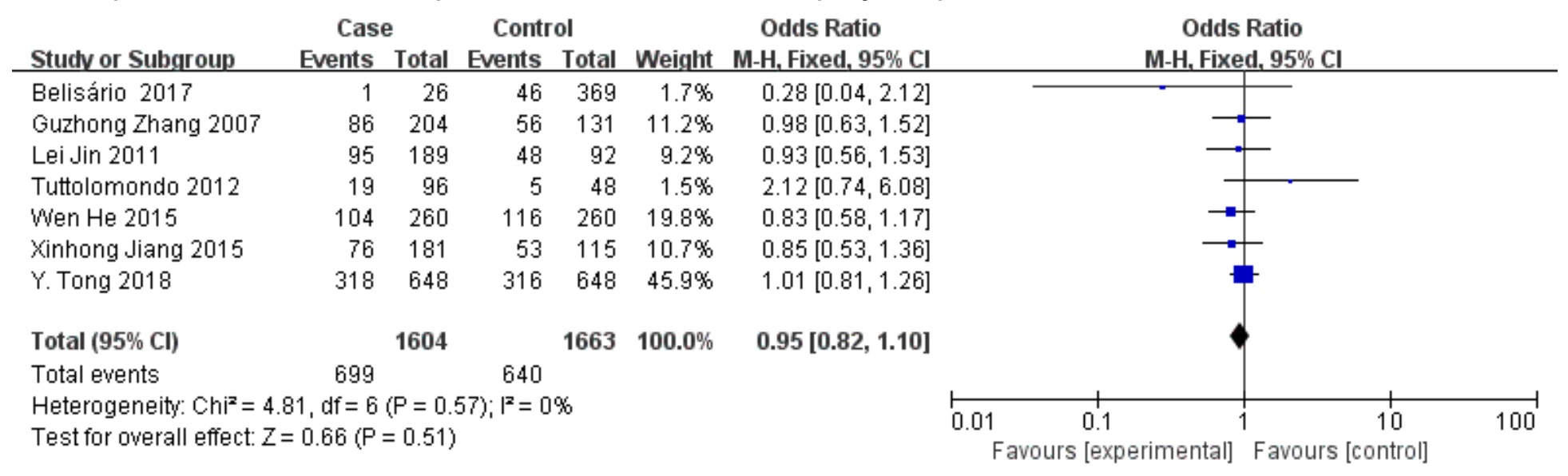

\section{Figure 9}

Forest plot for the relationship between IL-10-819C/T polymorphism and the risk of IS 


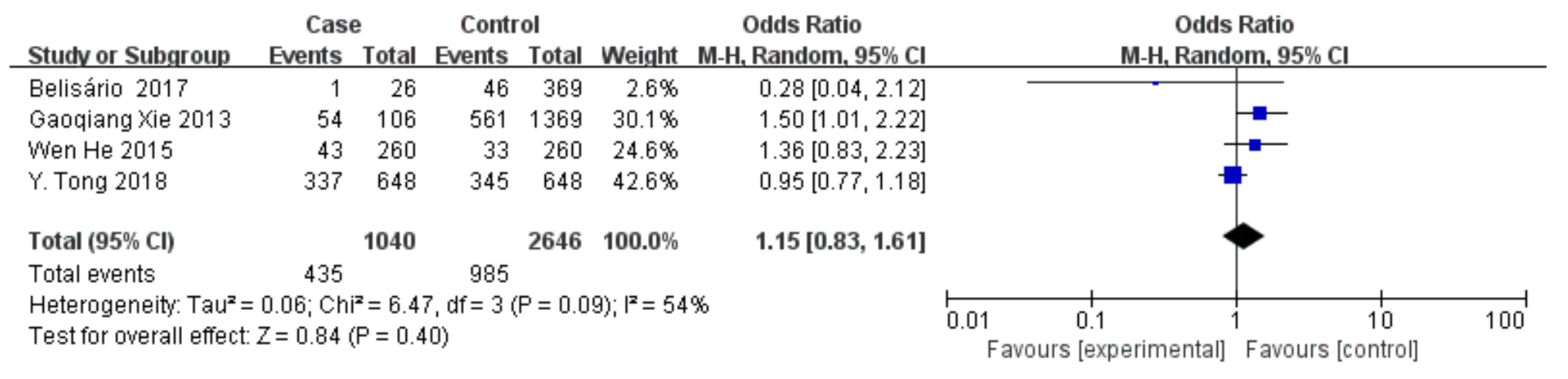

\section{Figure 12}

Forest plot for the relationship between IL-10- 592C/A polymorphism and the risk of I 